\section{Adenoid cystic carcinoma of Bartholin's gland: Report of a case and review of literature}

Sir,

Primary carcinoma of the Bartholin's gland, was first reported by Knob in 1864 . It comprises of $0.001 \%$ of the malignancies of the female genital tract and 0.1-5.0\% of vulvar carcinomas. ${ }^{[1,2]}$ Histologically Bartholin's gland carcinomas are classified as squamous cell carcinoma, adenocarcinoma, adenosquamous carcinoma, adenoid cystic carcinoma (ACC), transitional cell carcinoma, or small cell carcinoma. ACC constitutes approximately
$10-15 \%$ of all Bartholin' gland malignancies. ${ }^{[2]}$ It is an indolent tumor with marked tendency for local recurrences, which often precede distant metastasis by hematogenous spread usually to isolated organs like lung, liver, bone, brain, and kidney. ${ }^{[3-5]}$

A 45-year-old woman (P7L7MTP1, tubal ligation done 10 years back) presented with a swelling in the left vulvar area of 1-year duration. Previous menstrual cycles were normal. On physical examination, a hard, tender mass was palpable in the left vulval area involving left parametrium. Vaginal mucosa was intact. Bilateral inguino femoral lymph nodes were nonpalpable. Transperineal ultrasound showed $4.4 \times 5.3 \times 4 \mathrm{~cm}$ well-defined hypo echoic mass lesion in the left vulva. Rectum, urinary bladder, urethra, and cervix were separate from the lesion. Computed axial tomography (CAT) scan revealed $4.6 \times 5.2 \times 4.1 \mathrm{~cm}$ 
enhancing, well-defined mass in the left vulvar area [Figure 1]. Incision biopsy revealed ACC. Wide local excision of the tumor along with left labium majus, minora, and lower one-third of left vaginal wall with surrounding soft tissue was performed and vaginal reconstruction was done by pedicle-based superior gracillis muscle flap.

Grossly, the grayish white, solid and hard tumor measured $5 \times 5 \times 4.5 \mathrm{~cm}$ [Figure 2]. Microscopic examination displayed archetypal "cribriform pattern" characterized by rounded nests of cells arranged around gland-like spaces, which contained granular basophilic material. The latter was periodic acid Schiff positive and diastase-resistant The basaloid cells with little cytoplasm, had round to oval dark and hyperchromatic nuclei without nucleoli. The tumor exhibited little mitotic activity.

Extensive perineural invasion was present. Transition from normal glandular epithelium to neoplastic one was not identified. Immunohistochemically, the basaloid cells expressed S100 protein, while material inside

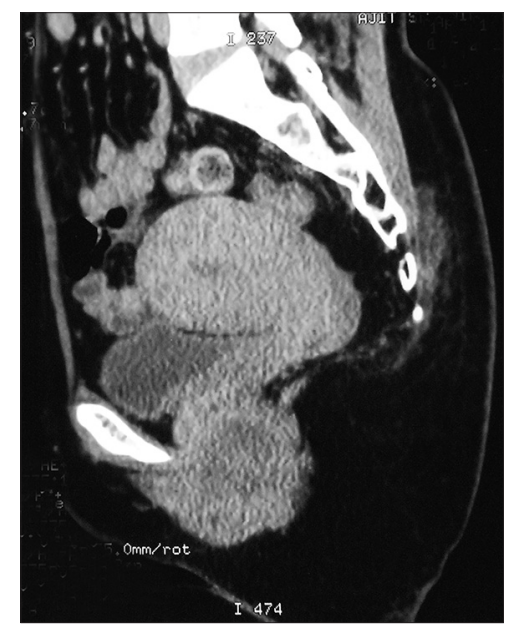

Figure 1: Computed axial tomography scan showing $4.6 \times 5.2 \times 4.1 \mathrm{~cm}$ enhancing, well-defined mass in the left vulvar area

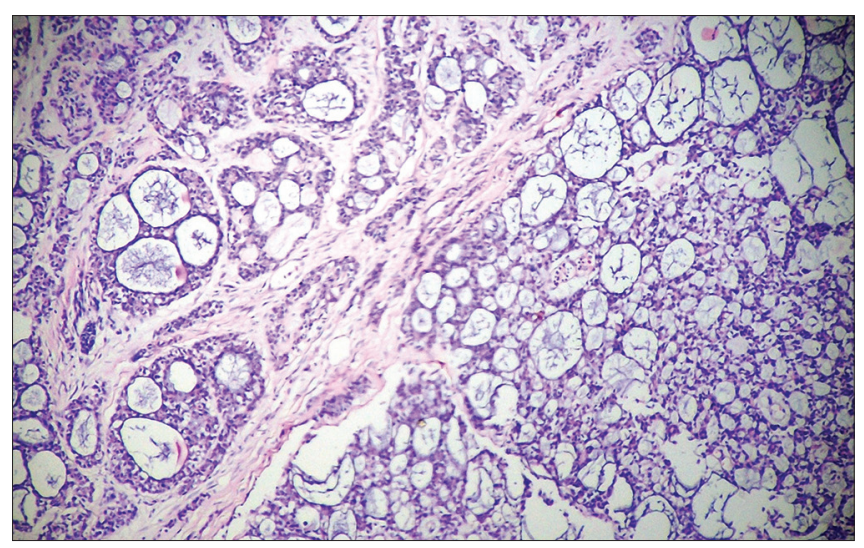

Figure 2: Photomicrograph (Hemotoxylin and Eosin stain, $\times 40$ ) showing "cribriform pattern" characterized by rounded nests of cells arranged around gland-like spaces, which contained granular basophilic material the fenestrated tumor nests and surrounding basement membrane was immunoreactive for type IV collagen. The resection margins were clear.

Bartholin's gland ACC is almost always solitary, unilateral, symptomatic tumor, primarily found in perimenopausal or postmenopausal women. The earliest symptoms are persistent pruritus and burning sensation attributable to a marked propensity for perineural invasion.

The classic histological pattern is "cribriform", which allow an accurate diagnosis on $\mathrm{H}$ and $\mathrm{E}$ stain. Nonetheless some special stains may be supportive. Most of the gland-like spaces are not true glandular spaces but instead represent extracellular cavities containing reduplicated basal laminar material as well as myxoid material produced by the tumor cells.

Most authors advocate surgery as initial line of treatment, nevertheless there is lack of consensus on the best surgical management protocol of Bartholin's gland ACC because of rarity and the lack of well-defined prognostic factors. ${ }^{[4,5]}$ The aim of surgical procedure is to achieve clear resection margins so as to attain at least a local cure, and thus reducing the rate of recurrence and reintervention rates. ${ }^{[3]}$

Shantilal M. Sisodia, Wasif Ali Zafar Ali Khan, Sameer A. H. Ansari, Vinod Mahajan Department of Pathology, Grant Medical College and Sir J. J. Group of Hospitals, Mumbai, Maharashtra, India

Correspondence to: Dr.Wasif Ali Zafar Ali Khan, E-mail: kwasifali@gmail.com

\section{References}

1. Rosenberg P, Simonsen E, Risberg B. Adenoid cystic carcinoma of Bartholin's gland: A report of five new cases treated with surgery and radiotherapy. Gynecol Oncol 1989;34:145-7.

2. Wilkinson EJ, Teixeira MR. Epithelial tumours. In: Tavassoli FA, Devilee $P$, editors. Pathology and genetics of tumours of the breast and female genital organs. World Health Organization Classification of Tumours. Lyon, France: IARC Press; 2003. p. 316-25.

3. Copeland LJ, Sneige N, Gershenson DM, Saul PB, Stringer CA, Seski JC. Adenoid cystic carcinoma of Bartholin's gland. Obstet Gynecol 1986;67:115-20.

4. Yang SY, Lee JW, Kim WS, Jung KL, Lee SJ, Lee JH, et al. Adenoid cystic carcinoma of the Bartholin's gland: Report of two cases and review of the literature. Gynecol Oncol 2006;100:422-5.

5. DePasquale SE, McGuinness TB, Mangan CE, Husson M, Woodland MB. Adenoid cystic carcinoma of Bartholin's gland: A review of the literature and report of a patient. Gynecol Oncol 1996;61:122-5.

\begin{tabular}{|l|l|}
\hline \multicolumn{2}{|c|}{ Access this article online } \\
\hline Quick Response Code: & Website: \\
\hline & www.sajc.org \\
\cline { 2 - 3 } & \\
\hline
\end{tabular}

